Marquette University

e-Publications@Marquette

Economics Faculty Research and Publications

Economics, Department of

$1-1-1986$

\title{
Monetary Policy, Fiscal Policy, and Investment Spending: An Empirical Analysis
}

Abdur Chowdhury

Marquette University, abdur.chowdhury@marquette.edu

James S. Fackler

University of Kentucky

W. Douglas McMillin

Louisiana State University

Published version. Southern Economic Journal, Vol. 52, No. 3 (January 1986): 794-806. DOI. (C) 1986 Southern Economic Journal. Used with permission.

Abdur R. Chowdhury was affiliated with Bentley College at the time of publication. 


\title{
Monetary Policy, Fiscal Policy, and Investment Spending: An Empirical Analysis*
}

\author{
ABDUR R. CHOWDHURY \\ Bentley College \\ Waltham, Massachusetts \\ JAMES S. FACKLER \\ University of Kentucky \\ Lexington, Kentucky \\ W. DOUGLAS MCMILLIN \\ Louisiana State University \\ Baton Rouge, Louisiana
}

\section{Introduction}

It is commonly thought that one of the primary channels through which money has an impact upon aggregate demand and hence prices and output is through its effects upon investment spending. In a bare-bones Keynesian-type system, an increase in money affects investment primarily by reducing market interest rates. In a Monetarist-type system, in addition to this indirect effect, an increase in money may have more direct effects upon investment spending through direct substitution out of money into investment goods. ${ }^{1}$ In either approach the initial effects may be reinforced through accelerator effects. The change in aggregate demand generated by the change in investment spending will in turn alter the levels of output and prices. Expansionary fiscal actions may also alter investment spending by raising interest rates. However, this negative impact of expansionary fiscal actions on investment may be mitigated or even offset if the expansionary fiscal policy raises income and acceleration effects on investment are strong. The net effect of the expansionary fiscal action on investment spending is thus ambiguous.

The aim of this paper is to examine empirically the impact of monetary and fiscal policy actions on investment spending, and to thereby provide evidence on how monetary and fiscal policy effects are transmitted to the macroeconomy. However, rather than focusing

\footnotetext{
${ }^{*}$ An earlier version of this paper was presented at the Southern Economic Association meetings in November 1984. The authors thank Charles Hegji for his helpful comments.

1. As noted by B. Friedman [7] the transmission mechanisms for changes in money embedded in the general equilibrium models of Tobin [22] and Brunner-Meltzer [2] are essentially identical. In both models a change in the quantity of money upsets asset market equilibrium and sets off a chain of portfolio substitutions that ultimately affect the real sector of the economy.
} 
upon total investment spending, the impacts of monetary and fiscal actions on residential construction, fixed investment, inventory investment, and consumer durables expenditures are analyzed separately. Consumer durable expenditures are included since the decision to purchase consumer durables is conceptually similar to the investment decision of firms. Thus, we present "disaggregated" evidence on the relationships among monetary policy, fiscal policy and the major components of investment spending. A reduced form methodology is used in the empirical analysis. One reduced-form approach to analyzing the impact of the policy variables on investment spending is the estimation of St. Louis-type equations in which each type of investment spending is regressed on distributed lags of a monetary policy variable and a fiscal policy variable. This method has been employed by Rose [16; 17] to analyze the effects of monetary and fiscal policy actions on, among other things, consumer durables expenditures and various types of investment expenditures. However, even though this single equation approach has been frequently employed to analyze the macro effects of monetary and fiscal policy actions, the approach has been subjected to much criticism $[4 ; 8 ; 9 ; 15]$. Based upon these criticisms, an alternative approach is employed in this paper.

The alternative reduced-form approach used in this paper, which is less restrictive than the single-equation approach, is the vector autoregressive modeling technique proposed by Hsiao $[11 ; 12]$. The vector autoregressive (VAR) approach can be thought of as a system of reduced-form equations with a separate equation for each variable in the system. The initial analysis in this paper is based upon three-equation models that contain separate equations for a particular type of investment spending, a monetary policy variable, and a fiscal policy variable; accordingly, the first set of models represents disaggregated VAR analogues to the traditional St. Louis equation. Unlike the traditional St. Louis model, however, no a priori assumptions are made about the exogeneity of the policy variables. The specification of the models provides evidence on the Granger-causal relations among the variables of the system, and the estimated systems can be used to provide estimates of the strength of these relations based upon variance decompositions computed from the systems. The variance decompositions and their interpretation will be discussed later.

While the three-variable VARs provide an interesting comparison to the traditional St. Louis framework, recent work has called into question empirical results which exclude the rate of interest. Specifically, Sims [20] has recently shown that the addition of an interest rate to a vector autoregressive system that contains money, a price variable, and an output measure has significant implications for the role of money shocks in altering prices and output. Based upon Sims's results and upon the fact that interest rates are an important link in the Keynesian view between changes in money and investment spending, four variable systems in which an interest rate is added to the systems described above are also analyzed. As described in more detail later, the addition of an interest rate allows inferences about whether most of the impact of a change in money on investment works through interest rates or whether, in addition to this interest rate channel, direct substitution between money and investment goods is important. Further, the four-variable models allow at least informal assessment as to whether the relative potency of monetary policy, which is a standard St. Louis-type result, is robust in the presence of the interest rate, which provides the traditional Keynesian link between the real and financial sectors.

The modeling technique is discussed in section II, and the three and four variable 
models are presented in sections III and IV, respectively. Further discussion of the models is found in section $\mathrm{V}$, and the last section contains concluding comments.

\section{Estimation Procedure ${ }^{2}$}

The methodology used to estimate the trivariate models analyzed here is the vector autoregressive technique suggested by Hsiao [11;12] and extended by Caines, Keng, and Sethi [3]. The VAR modeling technique is employed rather than a single equation or a structural model approach, since the VAR models avoid imposing potentially spurious a priori constraints (such as, for example, exogeneity of the monetary variable in the investment equations) on the model. The VAR technique employed involves the use of the Granger-causality definition in conjunction with Akaike's final prediction error criterion to impose restrictions on the estimation of the VAR. The technique allows each variable to depend upon a subset of the variables in the system and allows for different lag lengths for each variable in each equation.

The VARs estimated in the manner described above differ from the unconstrained VARs estimated by Sims [19; 20], Fischer [6], and Dwyer [5] in which each variable depends upon all other variables in the system with the same lag length. One problem that emerges in the estimation of a Sims-type VAR is that lengthening the common lag by one increases the number of parameters to be estimated by the square of the number of variables and thus rapidly depletes the degrees of freedom available for estimation. The degrees of freedom problem becomes significant in estimating Sims-type systems since the lag length must be kept generous in order to avoid under-specifying the lag for one or more of the variables and thereby avoiding biased coefficient estimates. Further, there is no reason to believe that the same lag length is appropriate for all variables in each equation.

The use of VARs to analyze our data set is motivated by Fischer's $[6,402]$ observation that vector autoregressions are ". . a convenient way of summarizing empirical regularities and perhaps suggesting the predominant channels through which relations work." Furthermore, Sims [21, 138], in a discussion of his VAR results, notes that “. . . careful attention to the historical data exerts an important discipline on what can be plausibly asserted about the way the economy works." However, the VAR is a reduced-form technique and it is thus difficult, based upon VAR results, to distinguish sharply among structural hypotheses.

The Lucas critique is also potentially applicable to the VAR technique, and it is assumed in this paper that there were no changes in policy regimes over the estimation period. As Sims [21, 138] notes, "The U.S. postwar data contains enough information to give a useful characterization of the conditional distribution of the future of major macroeconomic aggregates given the past. Although there is evidence that this structure changes over time, there is also evidence that it does not change suddenly, so that a model fit to the whole postwar period as if its parameters were fixed over that whole period is not badly biased because of parameter changes."

Since the theory underlying the estimation of the VAR is based upon the use of stationary data $[12 ; 18]$, the first step in the Hsiao procedure is to suitably transform the data to achieve stationarity. The specific transformations used in this study are discussed in the next

2. The material in this section is taken primarily from McMillin-Fackler [14]. 
section; at this point it is sufficient to emphasize that stationary data are used. Details of the Hsiao procedure are provided in McMillin-Fackler [14] and will not be discussed here.

\section{Disaggregated “St. Louis” Equations}

Presented in this section are models of the major components of investment spending which are disaggregated, VAR analogues to the traditional St. Louis methodology. Quarterly data for nominal consumer durable expenditures, nominal fixed investment expenditures, nominal inventory investment spending, the M1 definition of the money stock, nominal high employment government expenditures, and Moody's AAA corporate bond rate are used to estimate the various models. The corporate bond rate is employed as the relevant interest rate since, presumably, it is a long term rate that is most relevant for expenditures on longlived assets. ${ }^{3}$ M1 is chosen since it is the money stock definition that receives the most attention in monetary policy discussions. High-employment government expenditures are employed since this measure is designed to be purged of feedback from the current state of the economy to government expenditures. Variations in this measure are then the consequence of changes in spending programs. ${ }^{4}$

As pointed out in section II, specification and estimation of the VARs requires stationary data. The stationarity tests described in Ali-Thalheimer [1] and a simple test in which the transformed series was regressed on a constant and time were employed to determine what transformations were required to achieve stationarity. In the latter test, if the coefficient on time was statistically significant, further transformations were deemed necessary. For durable expenditures, a first difference of log transformation was required to achieve stationarity while for the other investment measures and for money and high employment expenditures, a second difference of log transformation was required to obtain stationary series. In the case of the corporate bond rate, it was found that a first difference of $\log$ transformation of this series was stationary. ${ }^{5}$

In the VARs estimated here only lagged values of the system variables appear as righthand variables in the system's equations. Following Hsiao [12], it is assumed that any contemporaneous relationships are reflected in the correlation of error terms across the system's equations. Based upon this assumption, full-information maximum likelihood (FIML) is used to estimate the system. The specification of each model is checked by over- and underfitting the system, estimating the modified systems by FIML, and then carrying out likelihood ratio tests of the adequacy of the specified system against each proposed modification. The likelihood ratio statistics are computed as $-2 \log \left(L^{c} / L^{u}\right)$ where $L^{c}$ is the maximized likelihood of the constrained system (the modified system for under-fits but the specified

3. A model for residential construction expenditures was also estimated using the secondary market yield on FHA mortgages as the relevant interest rate. The results are not qualitatively different from the system presented here using the AAA rate. We do not report the model using the FHA rate due to the generally different characteristics of FHA mortgages compared with, say, conventional mortgages.

4. Data for residential construction expenditures, non-residential construction expenditures, and durable goods expenditures are taken from the Survey of Current Business. Data for M 1 and high-employment expenditures are from the Federal Reserve Bank of New York, and data for the AAA bond rate and the secondary market yield on FHA mortgages are from the Citibank data tape.

5. The Ali-Thalheimer test suggested the presence of non-stationary seasonal variations in the AAA bond rate. As a consequence, seasonal differences were taken before further transformations were examined. 
system for over-fits) and $L^{u}$ is the maximized likelihood of the unconstrained system (the specified system for under-fits and the modified system for over-fits). This statistic asymptotically follows a chi-square distribution with $n$ degrees of freedom, where $n$ is the number of imposed contraints.

Using the estimation procedure described in section II, the three variable VAR model for fixed investment expenditures, estimated over the period 1959:1-1979:4 ${ }^{6}$, is

$$
\left[\begin{array}{c}
F I_{t} \\
M I_{t} \\
E H E_{t}
\end{array}\right]=\left[\begin{array}{ccc}
a_{11}^{3}(L) & a_{12}^{6}(L) & a_{13}^{1}(L) \\
a_{21}^{2}(L) & a_{22}^{4}(L) & 0 \\
0 & 0 & a_{33}^{3}(L)
\end{array}\right]\left[\begin{array}{c}
F I_{t} \\
M I_{t} \\
E H E_{t}
\end{array}\right]+\left[\begin{array}{c}
a_{1} \\
a_{2} \\
a_{3}
\end{array}\right]+\left[\begin{array}{c}
e_{1} \\
e_{2} \\
e_{3}
\end{array}\right]
$$

where $F I_{t}$ is the second difference of the log of fixed investment expenditures, $M I$ is the second difference of the log of the narrow money stock, $E H E$ is the second difference of the $\log$ of high employment expenditures, $a_{i j}^{k}$ represents the $k$ lag coefficients on variable $j$ in equation $i$, the $a_{i}$ are constants, and the $e_{i}$ are error terms. As Sims [19] has noted, it is difficult to interpret the individual autoregressive coefficients because of the reduced form nature of the model; these coefficients are not reported here but are available on request.

The adequacy of this model is tested by over- and under-fitting the system and then conducting likelihood ratio tests of the modified systems against system (1). These tests are presented in Table I and are interpreted in the following way: hypotheses (a)-(c) impose zero restrictions on the non-zero off-diagonal elements and hypotheses (d)-(f) ease the zero restrictions on the zero off-diagonal elements. We see that the zero restrictions in (a)-(c) are rejected while the tests of hypotheses (d)-(f) suggest that the zero restrictions of system (1) are appropriate. Tests of hypotheses $(\mathrm{g})-(\mathrm{k})$ suggest that shorter lags on the respective variables are inappropriate. Tests of hypotheses (l)-(s) suggest that extending the lags on the non-zero elements of the system never generates a significant improvement in the system. Although other hypothesis tests are possible, the tests reported in Table I indicate that system (1) appears to be an adequate VAR representation of the three variables under study.

The implications of system (1) will now be discussed. As Granger [10] proved, a zeroelement in the off-diagonal elements of a system like (1) indicates the absence of direct Granger-causality from one variable to another. Thus we see that both $M I$ and $E H E$ Granger-cause $F I$. However, there appears to be feedback from $F I$ to $M I$, which may represent Federal Reserve concern for a key element in the business cycle, spending on plant and equipment. However, neither $F I$ nor $M I$ feeds back into our measure of fiscal policy, EHE.

Sims [21] has recently argued that the strength of the Granger-causal relations can be measured from variance decompositions. Variance decompositions (VDCs) show the proportion of forecast error variance for each variable that is attributable to its own innovations and to shocks to the other system variables. As Sims [21, 131] notes, "A variable that is optimally forecast from its own lagged values will have all its forecast error variance accounted for by its own disturbances." Thus if either $M I$ or $E H E$ explain only a small portion of the forecast error variance of $F I$, we will interpret this as evidence of a weak Grangercausal relation.

6. The sample period ends in 1979 because of a switch by the Federal Reserve in October from an interest rate operating guide to a reserves oriented operating guide. Strictly speaking, the sample should end in 1979:3, but the additional observation had no effect on the results. 
Table I. Tests of Model Adequacy, Equation System $1^{\text {a }}$

Hypothesis
(a) $a_{12}(L)=0$

(b) $a_{13}(L)=0$

(c) $a_{21}(L)=0$

(d) $a_{23}^{4}(L)$

(e) $a_{31}^{4}(L)$

(f) $a_{32}^{4}(L)$

(g) $a_{1 \mathrm{r}}^{1}(L)$

(h) $a_{12}^{4}(L)$

(i) $a_{11}^{1}(L), a_{12}^{4}(L)$

(j) $a_{22}^{2}(L)$

(k) $a_{33}^{1}(L)$

(l) $a_{11}^{5}(L)$

(m) $a_{12}^{8}(L)$

(n) $a_{13}^{3}(L)$

(o) $a_{11}^{5}(L), a_{12}^{8}(L), a_{13}^{3}(L)$

(p) $a_{21}^{4}(L)$

(q) $a_{22}^{6}(L)$

(r) $a_{21}^{4}(L), a_{22}^{6}(L)$

(s) $a_{3}^{\vdots}(L)$
Likelihood Ratio Statistic

$16.60^{*}$

$6.94 * *$

$9.76^{* *}$

1.74

0.74

0.32

$10.74^{* * *}$

$10.46 * *$

$20.32^{* * *}$

$9.10^{*}$

$8.74 *$

1.96

0.18

1.34

2.10

0.86

0.70

1.98

1.42

a. $*$ significant at .025 level.

$* *=$ significant at .01 level.

$* * *=$ significant at .005 level.

Variance decompositions for system (1) are generated in the manner described by Sims [20]. This method recognizes that, in general, the correlation of residuals across equations is not zero. In calculating the VDCs the variables are ordered in a particular fashion. Because of the cross-equation residual correlation, when a variable higher in the order changes, variables lower in the order are assumed to change. The extent of the change depends upon the covariance of the variables higher in the order with those lower in the order. Because of this the VDCs may be sensitive to the ordering of the variables so that it is useful to examine the VDCs based on several orderings.

Variance decompositions for system (1) are presented in Table II, part 1. The orderings reported reflect the primary focus of the paper on the effects of monetary and fiscal policy on investment. The orderings are: (1) $M I, F I, E H E$, and (2) $E H E, F I$, and $M I$. The VDCs are presented in Table II, 1.A. (first ordering) and Table II, 1.B. (second ordering). A twenty quarter horizon is employed in order to allow the dynamics of the system to be worked out. However, the results for the twenty quarter horizon do not differ in any substantive way 
Table II. Variance Decompositions - Three Variable Systems: Twenty Quarter Horizons

\begin{tabular}{|c|c|c|c|}
\hline \multicolumn{4}{|c|}{$\begin{array}{l}\text { 1. System: } F I, M I, E H E \\
\text { A: Ordering: } M I, F I, E H E\end{array}$} \\
\hline Relative & \multicolumn{3}{|c|}{ Explained by } \\
\hline Variation in & MI & $F I$ & $E H E$ \\
\hline$M I$ & 78.9 & 20.4 & 0.7 \\
\hline$F I$ & 30.4 & 51.4 & 18.2 \\
\hline$E H E$ & 3.0 & 2.8 & 94.2 \\
\hline
\end{tabular}

2. System: INV, $M I, E H E$

A: Ordering: $M I, I N V, E H E$

B: Ordering: $E H E, F I, M I$

\begin{tabular}{crrr} 
Relative & \multicolumn{3}{c}{ Explained by } \\
Variation in & $E H E$ & \multicolumn{1}{c}{$F I$} & $M I$ \\
\hline$E H E$ & 98.3 & 1.6 & 0.1 \\
$F I$ & 20.6 & 59.6 & 19.8 \\
$M I$ & 2.6 & 20.1 & 77.3
\end{tabular}

\begin{tabular}{ccrr} 
Relative & \multicolumn{3}{c}{ Explained by } \\
Variation in & $M I$ & $I N V$ & $E H E$ \\
\hline$M I$ & 98.0 & 1.6 & 0.4 \\
$I N V$ & 21.6 & 74.4 & 4.4 \\
$E H E$ & 0 & 1.4 & 98.6
\end{tabular}

B: Ordering: $E H E, I N V, M I$

\begin{tabular}{crcc} 
Relative & \multicolumn{3}{c}{ Explained by } \\
Variation in & $E H E$ & $I N V$ & $M I$ \\
\hline$E H E$ & 100.0 & 0 & 0 \\
$I N V$ & 10.6 & 70.4 & 19.0 \\
$M I$ & 1.9 & 4.2 & 93.9
\end{tabular}

3. System: RE, $M I, E H E$

A: Ordering: $M I, R E, E H E$

\begin{tabular}{cccc} 
Relative & \multicolumn{3}{c}{ Explained by } \\
Variation in & $M I$ & $R E$ & $E H E$ \\
\hline$M I$ & 100 & 0 & 0 \\
$R E$ & 10.2 & 83.6 & 6.2 \\
$E H E$ & 1.3 & 0 & 98.7
\end{tabular}

4. System: $D E, M I, E H E$

A: Ordering: $M I, D E, E H E$

\begin{tabular}{crrr} 
Relative & \multicolumn{3}{c}{ Explained by } \\
Variation in & $M I$ & $D E$ & $E H E$ \\
\hline$M I$ & 89.8 & 6.0 & 4.2 \\
$D E$ & 38.2 & 57.4 & 4.4 \\
$E H E$ & 1.2 & 0.4 & 98.4
\end{tabular}

B: Ordering: $E H E, R E, M I$

B: Ordering: $E H E, D E, M I$

\begin{tabular}{|c|c|c|c|c|c|c|c|}
\hline \multirow{2}{*}{$\begin{array}{l}\text { Relative } \\
\text { Variation in }\end{array}$} & \multicolumn{3}{|c|}{ Explained by } & \multirow{2}{*}{$\begin{array}{l}\text { Relative } \\
\text { Variation in }\end{array}$} & \multicolumn{3}{|c|}{ Explained by } \\
\hline & $E H E$ & $R E$ & $M I$ & & $E H E$ & $D E$ & $M I$ \\
\hline$E H E$ & 100 & 0 & 0 & $E H E$ & 100 & 0 & 0 \\
\hline$R E$ & 5.2 & 85.3 & 9.5 & $D E$ & 4.8 & 70.0 & 25.2 \\
\hline MI & 1.6 & 17.2 & 81.2 & MI & 9.5 & 4.0 & 86.5 \\
\hline
\end{tabular}

from VDCs for four, eight, twelve, and sixteen quarters. As a consequence, these VDCs are not reported here but are available on request. We see that regardless of the ordering the variance in $M I$ and $E H E$ is almost completely explained by their own innovations. In ordering A, money innovations explain about $30 \%$ of the variance of $F I$; this proportion drops to about $20 \%$ in ordering B. EHE explains about $18 \%$ of the variance of $F I$ in ordering A and about $21 \%$ in ordering B. $M I$ thus explains no less of the variance in $F I$ than does $E H E$; it appears that the effects of $M I$ on $F I$ are at least as important as $E H E$ in determining fixed investment.

The specification of the three-variable model for inventory investment is discussed next. The non-zero elements of the $I N V$ model, analogous to those of system (1), are: $a_{11}^{6}(L), a_{12}^{2}(L), a_{13}^{4}(L), a_{22}^{4}(L)$, and $a_{33}^{3}(L)$. To conserve space, the results of tests of model adequacy are not reported here but are available on request.

For the $I N V$ system, the Granger-causality implications of the system are somewhat different than for the $F I$ system. Specifically, both $M I$ and $E H E$ Granger-cause inventory investment and both are free of feedback from spending on inventories. The lack of feedback from $I N V$ to both $M I$ and $E H E$ is further evidenced by the fact that, for the twenty- 
quarter variance decompositions (Table II, 2), for both orderings virtually all of the variance in both $M 1$ and $E H E$ is explained by their own innovations. In addition, in ordering A, $M 1$ innovations explain about $22 \%$ of the variance in $I N V$ while in ordering B this percentage declines only marginally, to $19 \%$. EHE, in contrast, explains substantially less of $I N V$ variance, ranging from about $4 \%$ in ordering A to about $11 \%$ in ordering B. Thus, it appears that $M 1$ shocks dominate $E H E$ in explaining variability in $I N V$.

The specifications of the three-variable models for residential expenditures $(R E)$ and consumer durables expenditures $(D E)$ are now discussed. The non-zero elements of the model for $R E$ are: $a_{11}^{1}(L), a_{12}^{5}(L), a_{13}^{11}(L), a_{22}^{4}(L)$, and $a_{33}^{3}(L)$. The non-zero elements of the model for $D E$ are: $a_{11}^{1}(L), a_{12}^{6}(L), a_{13}^{8}(L), a_{21}^{8}(L), a_{22}^{4}(L)$, and $a_{33}^{3}(L)$. In order to conserve space, the results of the tests of model adequacy similar to those in Table I are not presented here but are available upon request from the authors. Based upon these tests, each model in judged adequate.

For $R E$, the Granger-causality implications of the system are identical to those for $I N V$. $R E$ are Granger-caused by both $M I$ and $E H E$ while both $M I$ and $E H E$ are free of feedback from the other system variables. From the twenty-quarter variance decompositions (Table II, 3), we see that for both orderings, most of the variance in both $M I$ and $E H E$ is explained by their own innovations. In ordering A, $M 1$ innovations explain about 10.2 percent of the variance in $R E$ while in ordering B this percentage drops only slightly to $9.5 \%$. $M 1$ thus explains substantially less of the variance in $R E$ than it does for $F I$. EHE, regardless of ordering, explains very little of the variation in $R E$; again, it appears that monetary shocks have a greater effect on $R E$ than do shocks to $E H E$. VDCs for four, eight, twelve, and sixteen quarters again do not differ substantatively from those in Table II. These results are also available on request.

The Granger-causality implications of the system for $D E$ are quite similar to those for $F I$ in that there is direct Granger-causality from $D E$ to $M 1$. However, from the variance decompositions in part 4 of Table II we see that regardless of the ordering, innovations in $D E$ explain very little of the variance in $M 1$. The Granger-causality from $D E$ to $M 1$ thus appears to be quite weak, and as before, money is essentially free of feedback from either $D E$ or $E H E$. $E H E$ are also free of feedback from either $D E$ or $M 1$. For ordering A, the amount of variation in $D E$ explained by $M 1$ is $38 \%$ while $E H E$ explains only $4.4 \%$ of the variation in $D E$. In ordering B, $M 1$ shocks explain $25 \%$ of the variation in $D E$ while shocks to $E H E$ explain only $5 \%$.

The results of the analysis above support the results of the highly-aggregated St. Louistype models that monetary policy generally dominates fiscal policy in accounting for unanticipated movements in various investment categories. In only one case (that of fixed investment) might it be argued that fiscal policy is as important as monetary policy in explaining the variability of the key sub-component of investment expenditures; in the others the relative importance of monetary policy is much more likely.

\section{Disaggregated “Keynesian” Equations}

Although the results of the analysis of the three-variable models are of interest, we recall that in the bare-bones Keynesian view of the monetary transmission mechanism, interest rates are the key link between changes in money and investment expenditures. We also 
recall that Sims [20] found that addition of an interest rate to a system that previously excluded such a rate lessened the ability of monetary shocks to explain variations in output and prices. Further, the Sims analysis is performed in the absence of any explicit fiscal policy variables so that the relative importance of monetary and fiscal policies, controlling for the interest rate, is still an open question. For these reasons we now turn to an analysis of four variable VARs in which an interest rate is added to each of the three variable systems previously discussed. These four variable models provide some evidence on the distinctions between the standard textbook Keynesian view of the monetary transmission mechanism and the standard monetarist conception of this process. If the standard textbook Keynesian view is correct, we would expect to find direct causality from money to interest rates and from interest rates to investment expenditures with no direct causality from money to investment. In the monetarist view, we would expect direct causality from money to investment as well as indirect causality from money to interest rates and from interest rates to investment.

Based upon the estimation technique described earlier, the four variable VAR model for fixed investment spending estimated over the period 1959:1-1979:4 is

$$
\left[\begin{array}{c}
F I_{t} \\
M I_{t} \\
A A A_{t} \\
E H E_{t}
\end{array}\right]=\left[\begin{array}{cccc}
a_{11}^{3}(L) & a_{12}^{6}(L) & a_{13}^{4}(L) & a_{14}^{8}(L) \\
a_{21}^{5}(L) & a_{22}^{4}(L) & a_{23}^{1}(L) & 0 \\
a_{31}^{3}(L) & a_{32}^{4}(L) & a_{33}^{12}(L) & 0 \\
0 & 0 & a_{43}^{4}(L) & a_{44}^{3}(L)
\end{array}\right]\left[\begin{array}{c}
F I_{t} \\
M I_{t} \\
A A A_{t} \\
E H E_{l}
\end{array}\right]+\left[\begin{array}{c}
a_{1} \\
a_{2} \\
a_{3} \\
a_{4}
\end{array}\right]+\left[\begin{array}{c}
e_{1} \\
e_{2} \\
e_{3} \\
e_{4}
\end{array}\right]
$$

where $F I, M I$, and $E H E$ are as previously defined, $A A A$ is the first difference of log transformation of the AAA corporate bond rate, $a_{i j}^{k}$ represents the $k$ lag coefficients on variable $j$ in equation $i$, the $a_{i}$ are constants, and the $e_{i}$ are error terms. The individual coefficient estimates are available on request. The adequacy of the model is assessed in the manner described earlier. These likelihood ratio tests indicate that system (2) appears to be an adequate representation of the four variables under study. In order to conserve space, these test results are not given here but are available upon request.

From (2), we see that $M 1, A A A$, and $E H E$ directly Granger-cause $F I$. In addition, there is indirect Granger-causality from $M I$ to $F I$ since $M I$ Granger-causes $A A A$. An interpretation of this pattern is that $M I$ affects $F I$ by altering interest rates and by direct substitution out of money balances into $F I$. Likewise, there is indirect Granger-causality from $A A A$ to $F I$ since $A A A$ Granger-causes $M 1$. This latter causality pattern may reflect Federal Reserve concern for financial market stability; several reaction function studies also provide evidence of such a concern by the Federal Reserve. See, for example, McMillinBeard [13] and the studies cited therein. In addition to direct Granger-causality from $M 1$ to $A A A$, we see that $F I$ also directly Granger-causes $A A A$. Variations in $F I$, by affecting aggregate output, alter money demand, and this variation in money demand would be expected to affect $A A A$. We also find that there is direct Granger-causality from $A A A$ to $E H E$, and, since $M I$ and $F I$ Granger-cause $A A A$, there appears to be indirect causality from these two variables to $E H E$. Thus, unlike the three-variable systems, there appears to be feedback from at least some of the systems' variables to $M I$ and $E H E$. The strengih of this feedback is assessed next.

Variance decompositions for system (2) are presented in Table III, part 1. Two orderings are employed; one ordering is $M I, F I, A A A$, and $E H E$ while the second ordering is 
Table III. Variance Decompositions - Four Variable Systems: Twenty Quarter Horizons

\begin{tabular}{|c|c|c|c|c|}
\hline \multirow{2}{*}{$\begin{array}{l}\text { Relative } \\
\text { Variation in }\end{array}$} & \multicolumn{4}{|c|}{ Explained by } \\
\hline & $M I$ & $F I$ & $A A A$ & $E H E$ \\
\hline$M I$ & 68.6 & 14.1 & 16.0 & 1.3 \\
\hline$F I$ & 21.4 & 54.9 & 6.6 & 17.1 \\
\hline$A A A$ & 20.1 & 12.1 & 66.3 & 1.5 \\
\hline$E H E$ & 0.1 & 0.3 & 2.6 & 97.0 \\
\hline
\end{tabular}

B: Ordering: $E H E, F I, A A A, M I$

\begin{tabular}{lrrrr} 
Relative & \multicolumn{5}{c}{ Explained by } \\
Variation in & $E H E$ & \multicolumn{1}{c}{$F I$} & $A A A$ & \multicolumn{1}{c}{$M I$} \\
\hline$E H E$ & 98.6 & 1.4 & 0 & 0 \\
$F I$ & 25.1 & 64.3 & 3.0 & 7.6 \\
$A A A$ & 2.6 & 14.5 & 70.1 & 12.8 \\
$M I$ & 1.7 & 24.2 & 18.9 & 55.6
\end{tabular}

3. System: $R E, M I, A A A, E H E$

A: Ordering: $M I, R E, A A A, E H E$

\begin{tabular}{lrrrc} 
Relative & \multicolumn{4}{c}{ Explained by } \\
Variation in & $M I$ & $R E$ & $A A A$ & $E H E$ \\
\hline$M I$ & 74.1 & 18.3 & 7.6 & 0 \\
$R E$ & 26.5 & 70.2 & 3.3 & 0 \\
$A A A$ & 30.2 & 16.4 & 53.4 & 0 \\
$E H E$ & 0.8 & 2.4 & 6.2 & 90.6
\end{tabular}

B. Ordering: $E H E, R E, A A A, M I$

\begin{tabular}{lrrrr} 
Relative & \multicolumn{4}{c}{ Explained by } \\
Variation in & $E H E$ & \multicolumn{1}{c}{$R E$} & \multicolumn{1}{c}{$A A A$} & $M I$ \\
\hline$E H E$ & 94.1 & \multicolumn{1}{c}{0} & 5.8 & 0.1 \\
$R E$ & 2.4 & 83.8 & 6.1 & 7.7 \\
$A A A$ & 1.1 & 7.0 & 68.3 & 23.6 \\
$M I$ & 1.8 & 11.3 & 14.5 & 32.4
\end{tabular}

2. System: $I N V, M I, A A A, E H E$

A: Ordering: $M I, I N V, A A A, E H E$

\begin{tabular}{lrrrc} 
Relative & \multicolumn{4}{c}{ Explained by } \\
Variation in & $M I$ & $I N V$ & $A A A$ & $E H E$ \\
\hline$M I$ & 77.1 & 8.6 & 14.3 & 0 \\
$I N V$ & 23.1 & 64.8 & 12.1 & 0 \\
$A A A$ & 21.5 & 8.3 & 70.2 & 0 \\
$E H E$ & 0.6 & 2.0 & 1.2 & 96.2
\end{tabular}

B: Ordering: $E H E, I N V, A A A, M I$

\begin{tabular}{lrrcc} 
Relative & \multicolumn{5}{c}{ Explained by } \\
Variation in & $E H E$ & \multicolumn{1}{c}{$I N V$} & \multicolumn{1}{c}{$A A A$} & \multicolumn{1}{c}{$M I$} \\
\hline$E H E$ & 100.0 & \multicolumn{1}{c}{0} & \multicolumn{1}{c}{0} & 0 \\
$I N V$ & 6.0 & 59.4 & 14.3 & 20.3 \\
$A A A$ & 2.9 & 3.3 & 77.1 & 16.7 \\
$M I$ & 0.8 & 17.8 & 11.1 & 70.3
\end{tabular}

4. System: $D E, M I, A A A, E H E$

A: Ordering: $M I, D E, A A A, E H E$

\begin{tabular}{lrrrr} 
Relative & \multicolumn{4}{c}{ Explained by } \\
Variation in & $M I$ & $D E$ & $A A A$ & $E H E$ \\
\hline$M I$ & 88.4 & 5.3 & 3.5 & 2.8 \\
$D E$ & 28.9 & 47.0 & 4.3 & 19.8 \\
$A A A$ & 41.2 & 18.4 & 35.2 & 5.2 \\
$E H E$ & 11.4 & 1.3 & 2.5 & 84.8
\end{tabular}

B. Ordering: $E H E, D E, A A A, M I$

\begin{tabular}{lrrrr} 
Relative & \multicolumn{4}{c}{ Explained by } \\
Variation in & $E H E$ & $D E$ & $A A A$ & $M I$ \\
\hline$E H E$ & 96.0 & 1.2 & 1.7 & 1.1 \\
$D E$ & 21.2 & 52.0 & 8.7 & 18.0 \\
$A A A$ & 6.3 & 21.0 & 38.3 & 34.4 \\
$M I$ & 9.0 & 4.5 & 12.7 & 73.9
\end{tabular}

$E H E, F I, A A A$, and $M 1$. The VDCs are presented in Table III, 1.A (first ordering) and Table III, 1.B (second ordering). Again, only the results for a twenty-quarter horizon are reported since these results were substantially the same as at shorter horizons of four, eight, twelve, and sixteen quarters. We see that in ordering A, $M 1$ shocks explain about $21 \%$ of the variation in $F I$, but this proportion drops to about $8 \%$ in ordering $B$. Thus, when the interest rate is included in the system, we find that the percentage of total variation in $F I$ explained by $M I$ drops to two-thirds to one-half that explained by $M I$ in the three variable system. This result is similar to that in Sims [20] although the system variables are quite different. As in the three-variable $F I$ system, fiscal policy appears to be at least as important as monetary policy in explaining the variability of fixed investment spending. Further, the presence of the interest rate does not appreciably alter the impact of $E H E$ on $F I$. We also see that $M I$ shocks explain a much larger fraction of the variation in $A A A$ regardless of the 
ordering of the variables; fiscal policy, however, has little apparent impact on interest rates, an interesting result in light of recent discussion about the role of government finance in influencing the financial markets.

The specifications of the four variable models for inventory expenditures, residential expenditures, and consumer durables expenditures will now be discussed. The non-zero elements of the $I N V$ model are: $a_{11}^{6}(L), a_{12}^{2}(L), a_{13}^{4}(L), a_{22}^{4}(L), a_{23}^{1}(L), a_{31}^{5}(L), a_{32}^{9}(L), a_{33}^{12}(L)$, $a_{43}^{4}(L)$, and $a_{44}^{3}(L)$. The non-zero elements of the model for $R E$ are: $a_{11}^{1}(L), a_{12}^{5}(L), a_{13}^{3}(L)$, $a_{22}^{4}(L), a_{23}^{1}(L), a_{31}^{6}(L), a_{32}^{9}(L), a_{33}^{12}(L), a_{43}^{4}(L)$, and $a_{44}^{3}(L)$. The non-zero elements of the model for $D E$ are: $a_{11}^{1}(L), a_{12}^{6}(L), a_{13}^{4}(L), a_{14}^{8}(L), a_{21}^{7}(L), a_{22}^{4}(L), a_{23}^{1}(L), a_{31}^{9}(L), a_{32}^{11}(L)$, $a_{33}^{12}(L), a_{43}^{4}(L)$, and $a_{44}^{3}(L)$. As before, tests of model adequacy suggest that each model is adequate, and the results of these tests are available upon request.

The Granger-causality results implicit in the $I N V$ and $R E$ systems are identical. Among the more interesting are the results that: (i) $E H E$ does not Granger-cause either $I N V$ or $R E$, either directly or indirectly; (ii) both $M I$ and $A A A$ exert independent influences upon $I N V$ and $R E$; and (iii) bidirectional causality exists between $A A A$ and $M I$ but there is no Granger-causality from high employment spending to the interest rate. Similar to the corresponding trivariate models, the estimated systems including the interest rate tend to support a disaggregated St. Louis-type conclusion regarding the relative effects of monetary and fiscal policies on key components of investment expenditures.

The conclusion reached above regarding the relative potency of monetary policy is reinforced by examining the variance decomposition results; see Table III, parts 2 and 3 . For the inventory investment system, innovations to $M 1$ account for at least $20 \%$ of the variance of $I N V$, regardless of the selected ordering, while $E H E$ explains at most $6 \%$. For the $R E$ system, $M I$ explains $26 \%$ of the variability in residential spending in ordering A, a proportion which declines sharply to about $8 \%$ in ordering B. However, even when $E H E$ is positioned first in the ordering, it only explains an apparently negligible $2 \%$ of $R E$ fluctuations.

The Granger-causality results for the $D E$ system are identical to those of the $F I$ system. $M 1$ and $A A A$ directly Granger-cause $D E$; however, although $E H E$ did not directly Granger-cause either $I N V$ or $R E$ in these four-variable systems, there is direct Grangercausality from $E H E$ to $D E$. One explanation of this result is that $D E$ are more responsive to variations in nominal income generated by changes in $E H E$ than are $F I$ or $R E$. In addition to the direct causality from $M I$ and $A A A$ to $D E$, there is again indirect causality from $M I$ to $D E$ through the effects of $M I$ on $A A A$ and from $A A A$ to $D E$ through the effects of $A A A$ on $M 1$. There is also direct Granger-causality from $D E$ to $A A A$ as well as from $M I$ to $A A A$. Likewise, $D E$ directly Granger-causes $M I$ as does $A A A$. Finally, there is direct causality from $A A A$ to $E H E$ as well as indirect causality from $M I$ and $D E$ to $E H E$ operating through their effects on $A A A$.

As before, the strength of these causality relations is assessed by examining VDCs for the $D E$ system. These VDCs are reported in Table III, 4.A and 4.B. $M 1$ again explains a substantial fraction of the variance of $D E$ and $A A A$ regardless of ordering. However, the proportion of the variation in $D E$ explained by $M I$ falls with the addition of the interest rate to the VAR model. Feedback from the other system variables to $M 1$ appears to be weak, although in the second ordering $A A A$ explains about $13 \%$ of the variation in $M 1$. EHE explains about $20 \%$ of the variation in $D E$ regardless of ordering. This result is also quite different from the VDCs for the three variable $D E$ system. However, unlike $M 1$, the addition 
of the interest rate to the system raised the proportion of the variance in $D E$ explained by $E H E$. $E H E$ does not explain much of the variance in $A A A$, a result similar to the other systems. Feedback from the other system variables to $E H E$ appears, as in the other systems, to be weak.

The results for our four-variable models suggest a number of conclusions. First, as in the three variable models in section III, monetary policy continues to dominate fiscal policy in terms of explaining disaggregated investment expenditures despite the explicit inclusion of the interest rate. Second, even in the presence of the interest rate, money invariably contributes to the explanation of the major components of investment, a result consistent with the "monetarist" transmission mechanism. Third, as in the three-variable systems, high employment expenditures are relatively unimportant in the determination of investment spending.

\section{Conclusions}

The aim of this paper has been to assess the impact of monetary and fiscal policy actions on investment expenditures. The initial analysis was conducted with three-variable vector autoregressive systems which contained a category of investment expenditures - fixed investment expenditures, inventory investment expenditures, residential expenditures, or consumer durable expenditures - along with the narrow money stock and high-employment government expenditures. Subsequent analysis was performed within a four-variable vector autoregressive framework which added an interest rate to the three-variable vector autoregressions.

In all of the three-variable and four-variable vector autoregressive systems, we found that $M 1$ Granger-causes investment expenditures. The variance decompositions based upon these systems suggest a nontrivial effect of $M I$ on investment. High employment expenditures were found to Granger-cause investment in all of the three-variable systems and in the four-variable systems for consumer durable expenditures and fixed investment. However, the variance decompositions suggest that $M 1$ typically has much stronger effects upon investment than do high employment expenditures. These results generally suggest that any causality from high employment expenditures to investment expenditures is relatively weak.

It should also be noted that when the interest rate was added to the systems, direct causality from $M I$ to investment was observed as was indirect causality from $M 1$ to investment through the effects of $M I$ on the interest rate. This result is suggestive that the broader view of the transmission mechanism in which there is direct substitution out of money balances into investment goods as well as an effect operating through market rates of interest is more appropriate than the view in which monetary actions affect investment spending solely by altering market interest rates.

Finally, we note that although in several of the systems there is direct as well as indirect Granger-causality from the other system variables to money and high employment expenditures, this feedback is very weak. The variance decompositions suggest that most of the variation in both $M I$ and high employment expenditures is explained by their own innovations. 


\section{References}

1. Ali, M. M. and R. Thalheimer, "Stationarity Tests in Time Series Model Building." Journal of Forecasting, 1983, 249-57.

2. Brunner, K. and A. Meltzer, “Money, Debt, and Economic Activity." Journal of Political Economy. Sept/Oct 1972, 951-77.

3. Caines, P. E., C. W. Keng, and S. P. Sethi, "Causality Analysis and Multivariate Autoregressive Modelling with an Application to Supermarket Sales Analysis." Journal of Economic Dynamics and Control, August 1981. 26798.

4. deLeeuw, F. and J. Kalchbrenner, "Monetary and Fiscal Actions: A Test of Their Relative Importance in Economic Stabilization: Comment." Federal Reserve Bank of St. Louis Review, April 1969, 6-11.

5. Dwyer, G. P., Jr., "Inflation and Government Deficits." Economic Inquiry, July 1982, 315-29.

6. Fischer, S., "Relative Shocks, Relative Price Variability, and Inflation." Brookings Papers on Economic Activity, 2, 1981, 381-431.

7. Friedman, B. M., "The Theoretical Nondebate About Monetarism," in The Structure of Monetarism, edited by T. Mayer. New York: W. W. Norton, 1978, pp. 94-112.

8. Goldfeld, S. M. and A. S. Blinder, "Some Implications of Endogenous Stabilization Policy." Brookings Papers on Economic Activity, 3, 1973, 585-644.

9. Gramlich, E. M., "The Usefulness of Monetary and Fiscal Policy as Discretionary Policy Tools." Journal of Money, Credit and Banking, May 1971, 506-32.

10. Granger, C. W. J., "Investigating Causal Relations by Econometric Models and Cross-Spectral Methods." Econometrica, July 1969, 424-38.

11. Hsiao, C., "Autoregressive Modelling of Canadian Money and Income Data." Journal of the American Statistical Association, September 1979, 553-60.

12. __ "Autoregressive Modelling and Money Income Causality Detection." Journal of Monetary Economics, January 1981, 85-106.

13. McMillin, W. D. and T. R. Beard, "The Short-Run Impact of Fiscal Policy on the Money Supply." Southern Economic Journal, July 1980, 122-35.

$\rightarrow \longrightarrow$ and J. S. Fackler, "Monetary vs. Credit Aggregates: An Evaluation of Monetary Policy Targets." Southern Economic Journal, January 1984, 711-23.

15. Modigliani, F. and A. Ando, "Impacts of Fiscal Actions on Aggregate Income and the Monetarist Controversy: Theory and Evidence," in Monetarism, edited by J. Stein. Amsterdam: North-Holland, 1976, 17-42.

16. Rose, P. S., "Policy Variables and the Components of Private Spending in the U.S. Economy." Business Economics, May 1972, 41-48.

17. _ "The Sectoral Lags of Monetary and Fiscal Policy." Mississippi Valley Journal of Business and Economics, Winter 1974-75, 1-13.

18. Sargent, T. J., "Estimating Vector Autoregressions Using Methods Not Based On Explicit Economic Theories." Federal Reserve Bank of Minneapolis Quarterly Review, Summer 1979, 8-15.

19. Sims, C. A., "Macroeconomics and Reality." Econometrica, January 1980, 1-48.

20. _ "Comparison of Interwar and Postwar Business Cycles: Monetarism Revisited." American Economic Review, May 1980, 250-57.

21. __ "Policy Analysis with Econometric Models." Brookings Papers on Economic Activity, 1, 1982, $107-52$.

22. Tobin, J., "A General Equilibrium Approach to Monetary Theory." Journal of Money, Credit, and Banking, February 1969, 15-29. 